\title{
Reflections on the Practicability of Translation Proper in Foreign Language Classes
}

\author{
Youcef BENAMOR \\ Department of English, Faculty of Foreign Languages \\ Abdelhamid Ibn Badis University, Mostaganem, Algeria
}

\begin{abstract}
:
Foregrounding the paramount role of translation to boost foreign language learning at all educational strata, this reflective paper investigates whether translation is deemed a means to teach foreign languages or an end to prepare foreign language learners as prospective professional translators. Precisely, this reflective analysis aims to discuss these two research questions: do foreign language teachers simply use some amateur translation activities to upgrade their learners' linguistic proficiency? Or do they find it necessary to teach translation models and techniques proper, targeting translational proficiency along with linguistic ability? Drawing on the researcher's experience and specialist authorship, translation approaches and techniques as related to foreign language teaching/learning and 2) translation pedagogy types that govern the appropriate selection of translation techniques are the foundational units of this analytic endeavour. This analysis revealed that the basics of most well-known translation approaches and techniques are genuinely present in diverse foreign language classes. Additionally, teaching these translation approaches and techniques for general linguistic aims and for specific professional purposes are two different contexts where the former is shaped by presenting some mere language-based translation techniques and the latter by teaching much more specialist and profession-related ones. This categorisation inescapably determines the quality and quantity of translation practice and the nature of the teacher-learner pedagogical contract, aiming at foreign language learning per se, translation proficiency or both. According to either context, teachers should be aware of translation basics or translation proper to avoid ad hoc instruction and 'translationese.'
\end{abstract}

Keywords: Foreign language teaching, translation approaches, translation pedagogy

Cite as: BENAMOR, Y. (2017). Reflections on the Practicability of Translation Proper in Foreign Language Classes. Arab World English Journal for Translation \& Literary Studies, 1(4). DOI: http://dx.doi.org/10.24093/awejtls/vol1no4.11 